\title{
Ambigüedades del Sexo, Clasificación, Diagnóstico y Tratamiento.
}

\author{
Dr. Edwin C. Hamblen \\ (Traducción del Dr. G. L. E.)
}

\begin{abstract}
Vamos a continuar con las ambigüedades del sexo y es una conferencia más o menos larga, puesto que vamos a ver los buenos y malos resultados en relación con este grupo de individuos que hemos visto durante los últimos 30 años. Vamos a proceder directamente con las láminas y como prólogo, repetimos algunas de las cosas que dijimos antes.
\end{abstract}

Los individuos que tienen unos genitales más o menos indiferentes presentan un problema en la asignación del sexo, el ideal para nosotros es una asignación de sexo inequívoca pronta basada en la morfología, en la potencialidad presumible del crecimiento de estos genitales y el pronóstico hecho en cuanto a las potencialidades, por medio de cirugía reconstructora de estos genitales. Cuando la asignación del sexo ha sido errada puede modificarse antes de los 18 meses de edad, sin traumas psicosexuales para el individuo, excepto aquellos traumas que son cultivados por los padres o por los familiares.

Después de que el sexo genérico ha sido establecido usualmente a los $2 \frac{1}{2}$ años, la reasignación de un sexo trae gran cantidad de secuelas psicológicas serias, en todos estos individuos; en cooperación con los padres; en cooperación con los consejeros y los guías espirituales de los padres y en unión de una gran cantidad de pensamientos serios, debe haber una planeación a largo plazo de la manera de tratar estos individuos. Los padres de los niños con genitales anormales deben ser aconsejados de que sus hijos tienen un sexo indeterminado y el término seudohermafroditismo y hermanofroditismo debe ser evitado. Por lo tanto la necesidad de la terapéutica final para completar este desarrollo 
de los órganos sexuales debe instituírse en forma temprana y con un programa para los hechos que se deben desarrollar tanto desde el punto quirúrgico como el endocrino. La cortisona o la hidrocortisona como terapéutica para la hiperplasia suprarrenal debe ser comenzada tempranamente; la extirpación del falo cuando sea necesario, en una paciente a la cual se le ha asignado el sexo femenino, debe ser hecha antes de que el sexo genérico esté establecido, además puede haber algún disturbio en el desarrollo de un sexo genérico normal, andrógenos apropiados o terapéutica estrogénica debe dársele cuando la pubescencia comienza y se aconseja laparotomía cuando existe una incertidumbre alrededor de la compatibilidad de las gónadas con el sexo asignado, que debe ser hecha durante la pubescencia con la extirpación de las gónadas contrarias antes de que los estigmas contrasexuales se produzcan.

En cuanto al plan de esta conferencia les presentaré a Uds. las historias de los pacientes que tienen ambigüedades; el tratamiento de estos pacientes ha sido negligente por muchos años y las historias muestran buenos resultados por el hecho de haber seguido un plan práctico, aceptando el sexo asignado cuando la paciente es vista muy tarde para la reasignación del sexo. Les presentaré casos ilustrativos de los 8 tipos de nuestra clasificación de ambigüedades de sexo.

Tomamos el tipo $\mathrm{N}^{0}$ 1. Seudohermafroditismo femenino debido a hiperplasia congénita de la suprarrenal, el aspecto cromatínico es positivo. Esta es una paciente de 30 años y medio de edad, cuando la vimos por primera vez; a la edad de 10 años tenía un aumento del clítoris, no había tenido períodos, con hirsutismo facial a la edad de 14 años, tratada con electrólisis efectiva. Desde los 16 años mostraba vello en el cuerpo, pero no tuvo guía médica hasta los 26 años. En 1949 se le hizo una laparotomía que mostró un útero poco desarrollado y ovarios prepubescentes sin ningún tumor suprarrenal. Al examen general encontramos caída del cabello en la región temporal, piel aceitosa, vello grueso en el cuerpo; no había desarrollo de los senos, aspecto muscular androide y un falo de $5 \mathrm{~cm}$. por $1.2 \mathrm{~cm}$., además de una vagina profunda, ella tenía una cromatina positiva, las gonadotropinas altas, los 17 cetosteroides eran de 43 a 35 miligramos cifras muy superiores a lo normal. 
En cuanto al tratamiento, se le administró el test de cortisona que fue positivo, los cetosteroides después de 3 o 4 días con dosis de 25 miligramos diarios de cortisona por boca, descendieron a lo normal y desde hace 6 años ha sido tratada con 25 miligramos de cortisona diarios que la ha mantenido en su dosificación de 17 cetosteroides, dentro de la tasa de lo normal de 4 a 7 miligramos. El crecimiento de los senos a un estado 3 ocurrió dentro de un corto tiempo con 9 meses de tratamiento, perdió el hirsutismo y la piel aceitosa; aconsejamos una cliteroidectomía pero la paciente se negó a aceptarla. Tuvo el primer período después de 14 meses de comenzado el tratamiento y una pubescencia normal, perdió la mayoría del vello en el cuerpo, aún tiene una voz ronca y además tiene períodos que son ovulatorios. Esta paciente puede quedar embarazada y en ella no hubo error en la asignación del sexo, pero hubiera podido haberlo como en muchas pacientes con hiperplasia suprarrenal. Se ven los buenos resultados de la terapéutica con cortisona. Nos preguntamos cuánto tiempo debe tomar cortisona? Y la respuesta es que ella debe tomar cortisona por toda la vida. Se ha suprimido la hiperplasia suprarrenal, habrá una reincidencia de la hiperplasia? Suprimiendo la cortisona después de un largo tiempo, probablemente la paciente tendrá atrofia suprarrenal y entonces necesita cortisona de todas maneras, fundamentalmente se tratan indefinidamente. Los estrógenos vinieron de la iniciación de una función ovárica normal debida a que el exceso de andrógenos fue suprimido por la cortisona. El falo que ella rehusó hacerse amputar y que no regresa bajo la terapéutica de cortisona, es un signo irreversible de virilización.

Tipo No 2. La siguiente paciente es una que se acomoda al tipo 2. Seudohermafroditismo femenino no debido a hiperplasia suprarrenal congénita, puede ser debida a una falla embriológica 0 puede resultar de virilización en útero. Esta gente es positiva en su cromatina. Una paciente vino a vernos en noviembre de 1956 y tenía 16 o 17 años. Había sido asignada al sexo masculino desde su nacimiento, había crecido como un niño hasta que fue vista en el hospital de Duke, no tenía precocidad sexual, el desarrollo de los senos comenzó a los 12 años y a la edad de 13 tuvo períodos cíclicos, alrededor de lo que ella llamaba su pene, siempre orinaba parada. La paciente, a pesar de que había nacido y crecido co- 
mo un niño, que fue educada en colegios masculinos y seguía la rutina de los niños, por alguna extraña razón se sentía como una niña.

Al examen encontramos una niña bien estrogenizada o individuo bien estrogenizado, usaba vestidos de hombre, había fusión de los labios, había un clítoris de $11 / 2$ por $2 \mathrm{cms}$., encontramos útero y ovarios en posición normal con una vagina de $12-7 \mathrm{cms}$. de profundidad y un cuello palpable. En cuanto a los datos del laboratorio, la cromatina era positiva, los 17 cetosteroides dentro de la tasa ginecoide 8,3 miligramos, de manera que aquí teníamos una falta de justicia en la asignación del sexo y en el crecimiento de este individuo. Qué debíamos hacer? Recuerden lo anotado previamente que no debíamos reasignar el sexo después de dos años y medio; pero qué podíamos hacer con una paciente como ésta? Debíamos tratar de hacer un pene, debíamos tratar de hacer un escroto y poner bolas plásticas cuando teníamos una paciente que obviamente era una niña que tenía función ovárica normal, qué podíamos hacer?

Es simplemente uno de los problemas que encontramos y que encontraremos de tiempo en tiempo, de tal manera que nosotros conversamos, investigamos y buscamos consejos de psiquiatras. Tenemos un psiquiatra que tiene un entrenamiento ginecológico y él decidió que podíamos reasignar el sexo de este individuo que tenía 17 años, hicimos de él una mujer, fue aceptada por los padres y felizmente por la paciente; el certificado de nacimiento fue cambiado, todo lo que tuvimos que hacer fué separar los labios e hicimos una mujer perfectamente bien, no había ni siquiera suficiente hipertrofia clitoridiana para recurrir a la cirugía o amputación; había una vulva perfecta, una buena vagina, una uretra que estaba en la localización normal femenina pero orinaba a través del pequeño defecto; cuando ocurrían sus períodos venían a través de la misma abertura de los labios. Afortunadamente conseguimos una buena adaptación de la paciente, como tenía parientes en otro sitio la enviamos a vivir con ellos de modo que no se convirtiera en una monstruosidad en la vecindad y ha hecho una buena adaptación, está ahora saliendo con gente del sexo opuesto. Todo lo que hicimos es lo que les refiero y nos sentimos muy contentos del éxito que tuvimos, a pesar de que viola- 
mos las leyes que les dí, pero algunas veces tenemos que hacerlo para ayudar esta clase de pacientes con el problema que ellos presentan.

Tipo $\mathrm{N}^{\circ}$ 3. Ahora tomamos alguno de nuestros hermafroditas masculinos que corresponden al tipo $\mathrm{N}^{\circ} 3$. Tienen genitales externos androides o ambiguos y genitales internos predominantemente ginecoides y un cuadro de cromatina negativo.

Un pequeñito nos visitó cuando tenía $4 \frac{1}{2}$ años de edad hace alrededor de 9 años. Al nacimiento fue asignado como mujer pero a los 3 meses el doctor de la localidad le reasignó el sexo masculino. En 1946 se le hizo una circuncisión; hasta el año pasado no había sido tratado por un endocrinólogo, ninguno de nosotros había tenido acceso a este paciente hasta hace aproximadamente un año. Había permanecido en el servicio urológico. En 1950 cuando el paciente fue visto en el hospital de Duke encontramos al examen general que era normal, tenía una estatura baja, poseía un pene circuncidado de más o menos $3 \frac{1}{2}$ cms., había hipospadias, no tenía escroto, además mostraba pliegues labioescrotales y una pequeña bolsa vaginal. Este paciente tenía $4 \frac{1}{2}$ años de edad ósea, las gonadotropinas eran de menos de una unidad en las 24 horas y los 17 cetosteroides eran normales para la edad, lo que descartó cualquier hiperplasia suprarrenal.

Se decidió hacer una laparotomía en este niño. Se le encontró un pequeño útero, cuello y trompas que fueron extirpados, el cérvix no se conectaba con la vagina, los testículos se encontraron en una localización pelviana conectados con los epididimos y con vasa pero los cordones eran muy cortos para la orquidopexia con reconstrucción del escroto, por lo tanto se eligió hacer una biopsia de los testículos y se encontró una variabilidad notoria en el tamaño de los túbulos, la mitad eran pequeños y la otra parecían grandes para la edad del paciente, mostraban como si hubiera habido un estímulo en ellos y contenían un tipo especial de materia coloide que nunca he visto en 30 años. En ellos el tejido intersticial del testículo era inmaduro y las células parecían como fibroblastos. Fue puesto en una terapéutica de testosterona por los urólogos tratando de aumentar este pene de tal manera que pudiera pensarse en reconstruír la uretra. Finalmente el ginecólogo fue llamado un año más tarde, el urólog’ había extirpado la 
bolsa vaginal de tal manera que pudiera liberar un poco de tejido que trató de usar en su intento en reconstruír una uretra y por primera vez el psiquiatra entró a actuar fundamentalmente. Pienso que para esta paciente hubiera sido mejor asignarle el sexo femenino. No sé qué piensen Uds. pero el urólogo se propuso un trabajo inmenso, porque no solo tenía que reconstruír una uretra sino que debía estar seguro de conseguir un pene suficientemente grande y formar un escroto; no se podían formar los testículos de tal manera que se debía poner una prótesis. Más tarde se habría tenido que hacer otra laparotomía, eventualmente en la pubescencia, con el objeto de extirpar estos testículos que fueron dejados en una laparotomía demasiado temprana. Estos procedimientos quirúrgicos están relacionados y si se hubiese dejado el sexo como originalmente fue asignado, el problema no hubiera sido tan difícil. Teníamos una bolsa vaginal, hubiéramos desarrollado en ésta una vagina funcionante, no hubiéramos unido el cuello y el útero puesto que no teníamos ovarios. En el momento de la pubescencia antes de que estos testículos empezaran a funcionar, el útero, el cérvix y los testículos se hubieran extirpado y se hubiera hecho una sola laparotomía.

El aspecto peculiar del testículo fue lo que me confundió bastante, esto es lo que esperábamos encontrar en un niño de este tamaño; tubos inmaduros sin cavidad y con solo una o dos capas de células germinales y un tipo fibroblástico de tejido intersticial que contenga o no células de Leydig, pero en cambio teníamos tubos adultos que contenían un tipo particular de coloide, el patólogo no me satisfizo a este respecto, ni conozco la explicación de este cuadro peculiar.

Presento además otro caso dentro del tipo 3 de seudohermafroditismo: tenemos un paciente de 17 años y 3/4 de edad cuando lo vimos por primera vez, no tenía problema en la asignación del sexo, se había desarrollado como un hombre, tenía testículos que no habían descendido, criptorquídicos, tenía una pubescencia normal y una actividad sexual normal para su edad y vino a vernos únicamente por dolor en el lado derecho de la fosa ilíaca; al examen no encontramos ginecomastia, había buena androgenización, un pene de tamaño normal hipospádico, un escroto bien desarrollado; al examen del semen había azoospermia, gonadotropinas altas alrededor de 30 unidades rata en $24 \mathrm{hs}$. lo que indicaba 
degeneración criptoquídica del testículo y los 17 cetosteroides eran bajos para un hombre, $3.6 \mathrm{mg}$. $/ 24 \mathrm{hs}$. A causa de su dolor en la fosa ilíaca derecha, se le hizo una laparotomía y en ésta encontramos un testículo izquierdo de 3 a $3 \frac{1}{2} \mathrm{cms}$. en el canal inguinal, más bien alto y asociado con una trompa de Falopio, pero no tenía epididimo. El testículo derecho con una trompa de Falopio se había torcido, estaba necrótico y era la causa del dolor de la fosa ilíaca derecha. de tal manera que se le extirpó el testículo por una razón obvia puesto que estaba necrótico, decidimos extirpar también el útero, el cérvix y la vagina superior que existía porque era un procedimiento lógico en un macho y luego hicimos un intento con el testículo izquierdo, no vimos ninguna razón por qué no debía ser extirpado puesto que no tenía epididimo, no tenía vasa, estaba sufriendo la degeneración criptorquídica, no había fertilidad de tal manera que no traía ningún resultado bueno descender este testículo sin epididimo y sin vasa, de tal manera que nuestro plan fue extirpar el testículo bueno si pudiéramos llamarlo así y luego poner una prótesis eventualmente en el escroto. Desgraciadamente un mes más tarde murió de obstrucción intestinal. El paciente estaba bien androgenizado y nunca había tenido problemas sexuales excepto el criptorquidismo. Acerca de su desarrollo genital, no hay ninguna duda acerca del sexo, el testículo llamado "el testículo bueno" del lado izquierdo que no tenía epididimo ni vasa solo un cuadro típico de degeneración criptorquídica con una fibrosis más o menos grande del túbulo con desaparición de todas las células germinales, solo que hay unas células de Sertolli y es una parte normal esencial en las células intersticiales con células de Laydig más o menos bien formadas, de tal manera que esto representaba un daño testicular irreversible y el otro testículo estaba necrótico, creímos que le hacíamos bien al paciente extirpándole todo esto.

Tipo $\mathrm{N}^{0} 4$. Venimos al tipo 4 de seudohermafroditismo masculino. Este es el tipo con genitales externos ambigüos o androides y genitales internos predominantemente androides, naturalmente con una cromatina negativa. Este paciente fue visto cuando tenía 14 o 15 años de edad, el sexo le había sido asignado como femenino y había crecido como una mujer; la pubescencia fue androide, hubo virilización y fue lo que la trajo a consulta.

$\mathrm{Al}$ examen encontramos hábito androide, una voz ronca, hir- 
sutismo corpóreo, vello púbico androide, un falo del tamaño del pene, con hipospadias y unas bolsas vacías, vagina con dos centímetros de profundidad; lamentamos que esta paciente no hubiera venido antes de que su voz cambiara y se sucedieran cambios irreversibles, lo que nos hizo pensar que el problema consistía simplemente en aceptarle el sexo asignado ya que la paciente estaba bien adaptada a él.

Los hallazgos del laboratorio mostraron: gonadotropinas aumentadas lo que mostraba que había una degeneración testicular, 17 cetosteroides dentro de la tasa masculina $15.7 \mathrm{mg} . / 24 \mathrm{hs}$. de tal manera que nos dirigíamos a hacer el diagnóstico de un seudohermafroditismo masculino. Hicimos una laparotomía, no encontramos genitales internos ginecoides, tenía dos testículos normales con epididimo y con vasa en la parte superior de los canales inguinales; pueden no estar de acuerdo con el cirujano, pero aceptamos el sexo originalmente creado, extirpamos los dos testículos y tratamos la paciente con estrógenos cíclicos para aumentar el desarrollo del sexo asignado, extirpamos el falo y le hicimos un ensanchamiento de la bolsa vaginal, que fue mantenida por actividad coital.

Aquí tienen otro tipo cuatro de seudo-hermafroditismo masculino con una historia mala, es una de las más tristes para con tarles. No había sido tratada por ningún endocrinólogo, no fue vista por el psiquiatra, fue tratada por los urólogos sin consulta ninguna. La paciente fue vista en 1936, había sido asignada al sexo femenino y había crecido como una niña en un Orfanato, no había tenido ningún problema personal durante la pubescencia hasta que la voz comenzó a ser ronca y tenía signos de pubescencia androide. $\mathrm{Al}$ examen encontramos un habitus androide, no había ginecomastia, ni vello sexual o corpóreo, el pene tenía $4.4 \mathrm{cms}$. con cuerpo e hipospadias, sí, esto era un pene, no había vagina, los labios escrotales eran bífidos, la gónada izquierda estaba localizada inguinalmente y podía descender, tenía $3 \mathrm{cms}$. de tamaño, había una gónada en la parte labioescrotal derecha de tamaño normal, de tal manera que el urólogo hizo una laparotomía para estar seguro de que no había genitales internos ginecoides que pudieran extirpar, no podía tomar otra decisión. El me lo dijo cuando hicimos la laparotomía, no encontramos genitales ginecoides y él me preguntó qué decisión iba yo a tomar; tomamos la de- 
cisión de acuerdo con las reglas antiguas de que si había testículo debíamos conformarnos a él y le reasignó el sexo como macho sin consejo del psiquiatra y luego se hicieron muchas operaciones con el fin de liberar los cuerpos cavernosos, reparar el hipospadias, además se le dio gran cantidad de hormonas para aumentar sus órganos de manera que se pudiera trabajar en estos procedimientos plásticos y cuando la pubescencia se hizo más tarde a pesar de toda la terapéutica androgénica este individuo tuvo ginecomastia lo que no agregó nada bueno al cuadro cuando llegó a los 21 años. Ha sido una fuente de intranquilidad para el urólogo, él lo ha buscado para amenazarlo y ha sido un individuo muy infeliz. Se agacha para orinar, no se ha adaptado y ha estado en todas las cárceles de nuestro Estado por razón de sus indiscreciones. Finalmente se casó, naturalmente no podía ser un matrimonio feliz y se divorció porque el padre de su esposa fue informado de su ineptitud: lo trajo a la corte informando de que su hija se había casado con un hermafrodita, de tal manera que ha sido un fracaso en todo sentido.

Cuando la vimos por primera vez creo que hubiera sido más fácil en 1936 continuar con el sexo asignado, con un poquito de cirugía hubiéramos dado mejores resultados; yo hubiera insistido en dejarla como una mujer, terminamos con un testículo abajo, un escroto bífido, gran cantidad de corrección del hipospadias pero no como para que la paciente deje de hacer la orina en cuclillas.

Tipo $\mathrm{N}^{0} 5$. Aquí tienen el tipo $\mathrm{N}^{0} 5$ de seudo-hermafroditismo masculino, en el cual la paciente tiene genitales externos ginecoides pero que es cromatin negativo. Esta paciente fue asignada como mujer. La vimos por primera vez a la edad de 15 años; había comenzado a desarrollar sus senos antes de haberla visto, no había androgenización. Los hallazgos clínicos mostraron un habitus ginecoide, senos estado I, vello axilar y un monte de Venus un poco androide, los genitales externos ginecoides a pesar de que tenía un falo de $3 \mathrm{cms}$. por $2 \mathrm{cms}$., una vagina de $2 \mathrm{cms}$. de profundidad y algo de bifidés en labio-escroto con gónadas en los canales inguinales; en el examen del laboratorio se encontró que las gonadotropinas estaban altas lo que nos demostró que había una degeneración criptorquídica, los 17 cetosteroides dentro del grupo masculino más alto, $27 \mathrm{mg}$./24 hs. a pesar de que no había 
androgenización. Resolvimos hacer laparotomía y no encontramos ningún genital interno ginecoide, ambas gónadas eran normales, sin epididimo ni vasa, elegimos aceptar el sexo asignado y extirpar estas gónadas a pesar de que no estaban virilizando, pensamos que si las dejábamos llegaban a convertirse en malignas, puesto que hay una alta incidencia de malignidad en testes criptorquídicos, habían estrogenizado a la paciente aunque no habían hecho el trabajo completo, por esto los testículos se extirparon. Al examen había una degeneración criptorquídica, la paciente se trató con estrógenos, tuvimos muy buen resultado y anticipamos que la paciente tenía que hacerse una vagina puesto que no tenía sino una de $2 \mathrm{cms}$. Los estrógenos que le dimos y la elegancia cosmética que desarrolló fue tan atractiva que comenzó a trabajar, se le hizo una vagina normal y amplia por todo sentido y últimamente se casó y ha hecho una buena adaptación sexual, de tal manera que aquí tienen buenos resultados. Ciertamente su hipertrofia clitoridiana era mínima y no requería ninguna cirugía y sin embargo está el cuadro de sus testículos que eran feminizantes y cuando los miramos no parecen diferentes de un testículo masculinizante, buenas células de Leydig, mucha fibrosis tubular, degeneración criptorquídica, algunas células de Sertolli y algo de espermatogonias.

Ahora llegamos al verdadero hermafroditismo y naturalmente más o menos el $75 \%$ de éstos son positivos en su parte cromatínica. Esta paciente fue vista por primera vez a los 22 años de edad, su historia indicaba que había sido asignada al sexo femenino y crecido como mujer, ella vino con vestidos de mujer, los padres habían ignorado las instrucciones del médico en el momento del nacimiento que cuando tuviera un año de edad se le debía reconsiderar el sexo, y siguió así. Cuando presentó la pubescencia fue androide, no hubo ginecomastia, no hubo hemorragia genital, cuando vino presentaba un hábito androide, con acné, barba, una voz ronca, vello grueso corporal, senos androides, un monte de venus androide, un falo de $8 \mathrm{cms}$. de largo con un meato uretral a $1 \mathrm{~cm}$. de la punta del glande, cuerpos cavernosos con escroto bífido, con gónadas escrotales bilaterales de $1 \mathrm{~cm}$. de tamaño. Sentí timidez cuando tuve que examinar esta paciente y encontrar estos genitales, había venido con la nota más sutil de referencia; el Dr. que la remitió nos mandó una nota: "podría identificar Ud. el sexo de esta paciente? Pues yo creo que ella será 
muy feliz con esto". En el laboratorio encontramos cromatina positiva, las gonadotropinas urinarias estaban ligeramente aumentadas pero no significantemente, los 17 cetosteroides estaban bien dentro de la tasa normal para el macho; qué hicimos aquí? No hicimos nada, y la razón para que no lo hiciéramos fue de que hubiéramos reasignado este nuevo sexo y extirpado lo que nos pareció un pene más o menos decente, el escroto con gónadas y tratar esto, la vagina era una cosa que hubiéramos podido hacer, debíamos revertir o reasignar el sexo y hacer este individuo un macho, el dato cromatínico positivo nos significaba que teníamos un hermafrodita verdadero. El psiquiatra nos aconsejó no hacer nada, ni biopsia testicular ni ningún movimiento a la paciente puesto que era una paciente peligrosa y la peculiaridad de esta era que no le importaba nada su situación, ella vino solamente porque el médico creyó que debía tener un chequeo. El sexo había sido completamente sublimado, no le parecía extraño tener vestidos femeninos y poseer un equipo masculino y lo mismo a los padres no les parecía nada extraño al respecto, no teníamos un concepto verdadero del problema, pertenecían a una secta religiosa peculiar lo que hacía este problema particular. Era de aquellos tipos fanáticos que tenemos en los E. U., tipos peculiares que tienen ideas raras acerca de la religión de la medicina y de la cirugía de tal manera que nos consideramos seguros de que esta paciente era un verdadero hermafrodita, pero no satisfacimos nuestro interés académico, para ver cuál de estos testículos era ovotestes, para probar su verdadero hermafroditismo, ni tratamos tampoco de revertir el sexo puesto que nadie estaba interesado, tampoco importaba asignar un verdadero sexo, de manera que dejamos a la paciente. A ella no le gustaban los hombres, el sexo era malo, tomar era malo lo mismo que fumar de manera que la dejamos sola.

Con otro verdadero hermafrodita decidimos hacer bien las cosas, porque la vimos temprano. Se le había asignado el sexo masculino al nacimiento y a los cuatro meses vino a nosotros para investigación puesto que sus familiares no estaban seguros de su sexo, por la naturaleza de sus genitales. Al examen ginecológico encontramos lo siguiente: esencialmente unos labios mayores normales, un falo moderadamente crecido, hipospadias, una bolsa vaginal muy poco profunda y una pequeña gónada en el labio derecho. El individuo era cromatínicamente positivo. A pesar del 
hecho de haber una gónada, hubo alguien que pensó que era una hiperplasia congénita suprarrenal y chequeamos la edad ósea, no estaban aumentados los 17 cetosteroides de tal manera que descartamos esta teoría. A los cuatro meses resolvimos hacer un cambio, consultando con el psiquiatra y con los padres reasignamos el sexo al de una mujer y cambiamos el certificado de nacimiento. Un año más tarde decidimos hacer algo acerca de sus genitales externos, extirpamos la gónada del labio derecho, aquí hay un error puesto que pensamos en gónada, no en gónadas. Al estudio de la gónada extirpada nos probó que se trataba de un ovotestes, desde entonces hemos cambiado nuestro diagnóstico a un verdadero hermafroditismo, hemos decidido no hacer nada hasta que la pubescencia ocurra y ver en qué forma la otra gónada va a trabajar, pero no vamos a hacer laparotomía. Si al tiempo de la pubescencia actúa como un testículo será extirpado inmediatamente, en la laparotomía puede ser que encontremos una trompa conectada con un ovario o con un cérvix y que podamos traer este cérvix hacia abajo y unirlo con la vagina y llegar a tener una mujer completamente feliz, ciertamente vamos a tener que desarrollar esta vagina pero no creemos que deba hacerse esta vagina hasta el tiempo en que llegue a la pubertad y se necesite o bien para coito o para drenar la sangre al estímulo ovárico. De modo que este es el plan en esta paciente; esencialmente un plan ideal si lo podemos llevar a cabo, reasignamos el sexo antes de que el sexo genérico estuviera en su mente. 